\title{
Does artificial intelligence for classifying ultrasound imaging generalize between different populations and contexts?
}

Tolsgaard, M G; Svendsen, M B S; Thybo, Jonathan Kistrup; Petersen, O B; Sundberg, K M; Christensen, Anders Nymark

Published in:

Ultrasound in Obstetrics and Gynecology

Link to article, DOI:

10.1002/uog.23546

Publication date:

2021

Document Version

Peer reviewed version

Link back to DTU Orbit

Citation (APA):

Tolsgaard, M. G., Svendsen, M. B. S., Thybo, J. K., Petersen, O. B., Sundberg, K. M., \& Christensen, A. N. (2021). Does artificial intelligence for classifying ultrasound imaging generalize between different populations and contexts? Ultrasound in Obstetrics and Gynecology, 57(2), 342-343. https://doi.org/10.1002/uog.23546

\section{General rights}

Copyright and moral rights for the publications made accessible in the public portal are retained by the authors and/or other copyright owners and it is a condition of accessing publications that users recognise and abide by the legal requirements associated with these rights.

- Users may download and print one copy of any publication from the public portal for the purpose of private study or research.

- You may not further distribute the material or use it for any profit-making activity or commercial gain

- You may freely distribute the URL identifying the publication in the public portal 
Does artificial intelligence for classifying ultrasound imaging generalize between different populations and contexts?

M. G. Tolsgaard ${ }^{(1,2)}$, M. B. S. Svendsen ${ }^{(1)}$, J. K Thybo ${ }^{(3)}$, O. B. Petersen ${ }^{(2,4)}$, K. M. Sundberg ${ }^{(2)}$, A. N. Christensen (3).

1) Copenhagen Academy for Medical Education and Simulation - Rigshospitalet, Center for Human Resources and Education, Capital Region of Denmark.

2) Department of Fetal Medicine, Rigshospitalet, Capital Region of Denmark.

3) Department of Applied Mathematics and Computer Science. Technical University of Denmark.

4) Department of Clinical Medicine, University of Copenhagen, Denmark. OBP holds a professorship funded by Novo Nordisk Foundation grant NNFSA170030576

\section{Contact information:}

Dr. Martin G. Tolsgaard; martin.groennebaek.tolsgaard@regionh.dk

Blegdamsvej 9, 2100-Copenhagen, Denmark.

This article has been accepted for publication and undergone full peer review but has not been through the copyediting, typesetting, pagination and proofreading process which may lead to differences between this version and the Version of Record. Please cite this article as doi: 10.1002/uog. 23546 
In a recent publication in this journal, Drukker et al. ${ }^{1}$ reviewed the role of Artificial Intelligence (Al) in ultrasound imaging in Obstetrics and Gynecology. The authors describe the application of $\mathrm{Al}$ algorithms for automated detection and classification of standard planes, among other applications. One particular challenge is that large amounts of ultrasound images are required to train these Al algorithms. The way the resulting algorithms are trained carries a risk of introducing bias. Secondly, a potential problem arises in the application of algorithms outside the context of the population of data on which the algorithms were trained and validated. There is currently insufficient evidence that $\mathrm{Al}$ algorithms generalize from the population they are trained on to other populations. It is problematic for the general adoption of research results if Al algorithms fail to generalise across different settings. We here describe how an Al algorithm developed in a British setting and using data from a British population in 2016 performs with images obtained in a Danish population across two fetal medicine centers between 2009 and 2017. 


\section{Methods}

We implemented the neural network architecture and weights published by Baumgartner et al. (SonoNet, 2017) ${ }^{2}$ in Pytorch, ${ }^{3}$ which is a modern framework for Al analyses.

Mid-trimester ultrasound scans were obtained from two fetal medicine centers in the Capital Region of Denmark, the scans were completed in the period between 2009 and 2017. The images included in our classifications were obtained on GE machines: Logiq7 (8\%), Voluson E7 (7\%), Voluson E8 (84\%), Voluson E10 (1\%). A total of 2048 images were manually annotated by one of the study authors (MGT). The images annotated as true standard planes were compared with the predictions made by SonoNet. The network in action was visualized using 'heatmaps'. Heatmaps were used to highlight pixels that were particularly important for the neural network in the classification of the specific image. The study was approved by the Danish Patient Safety Authority (3-30132915/1) and by the Data Protection Agency (P- 2019-310). 


\section{Results}

The resulting confusion matrix is shown in Figure 1. We found F1 scores (a measure of model accuracy) between 0.62 and 0.94 , with the highest performances demonstrated for transcerebellar view and abdominal circumference and lowest for RVOT and 3VV standard planes. The overall accuracy was $79.25 \%$.

Figure 2 illustrates the neural network in action. The heatmaps demonstrated that the neural network made little or no use of all information available when classifying standard planes (for example, not using the whole heart for classifying the four-chamber view but only the crux cordis). 


\section{Interpretation}

Our results are almost identical to those by Baumgartner et al. in the original evaluation of the $\mathrm{Al}$ algorithm for standard plane detection in mid-trimester ultrasound scans. This finding is promising because it suggests that the barriers for adopting Al algorithms across different populations, ultrasound equipment, ultrasound operators, and technical frameworks are low.

In other words, our findings provide evidence of external validity of Al algorithms by suggesting that performance of the initial creation of an algorithm in one context is replicated when adopting the algorithm to a new population, annotated by different experts, and implemented in a new programmatic framework. 


\section{References}

1. Drukker L, Noble JA, Papageorghiou AT. Introduction to artificial intelligence in ultrasound imaging in obstetrics and gynecology [published online ahead of print, 2020 Jun 12]. Ultrasound Obstet Gynecol. 2020;10.1002/uog.22122. doi:10.1002/uog.22122

2. Baumgartner CF, Kamnitsas K, Matthew J, Fletcher TP, Smith S, Koch LM, Kainz B, Rueckert D. SonoNet: Real-Time Detection and Localisation of Fetal Standard Scan Planes in Freehand Ultrasound. IEEE Trans Med Imaging. 2017;36(11):2204-2215. doi:10.1109/TMI.2017.2712367

3. Paszke A, Gross S, Massa F, Lerer A, Bradbury J, Chanan G, Killeen T, Lin Z, Gimelshein N, Antiga L, Desmaison A, Köpf A, Yang E, DeVito Z, Raison M, Tejani A, Chilamkurthy S, Steiner B, Fang L, Bai J, Chintala S. Pytorch: An imperative style, high-performance deep learning library. In Advances in neural information processing systems. 2019:pp. 8026-8037. 
Figure 1. The confusion matrix demonstrates number of standard plane images classified using the neural net (SonoNet) versus manual annotation. The neural net failed at distinguishing reliably between some standard planes (3VV and RVOT), whereas other planes were classified with high accuracy (e.g. femur length or abdominal circumference).

Figure 2. An example of visualizations using 'heat maps'. To the left: Correctly classified four chamber view. To the right: Correctly classified transcerebellar plane. In both images, the neural network only used part of the images for classification (only crux cordis and not the apex; only the cerebellum but not the anterior complex), in contrast to the criteria used by human experts. 


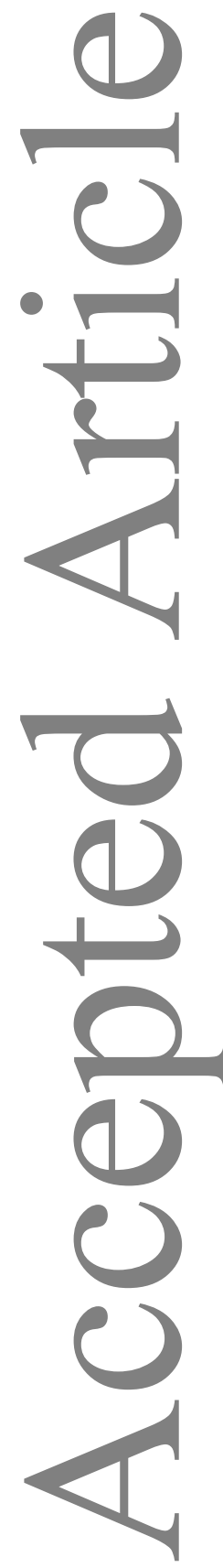

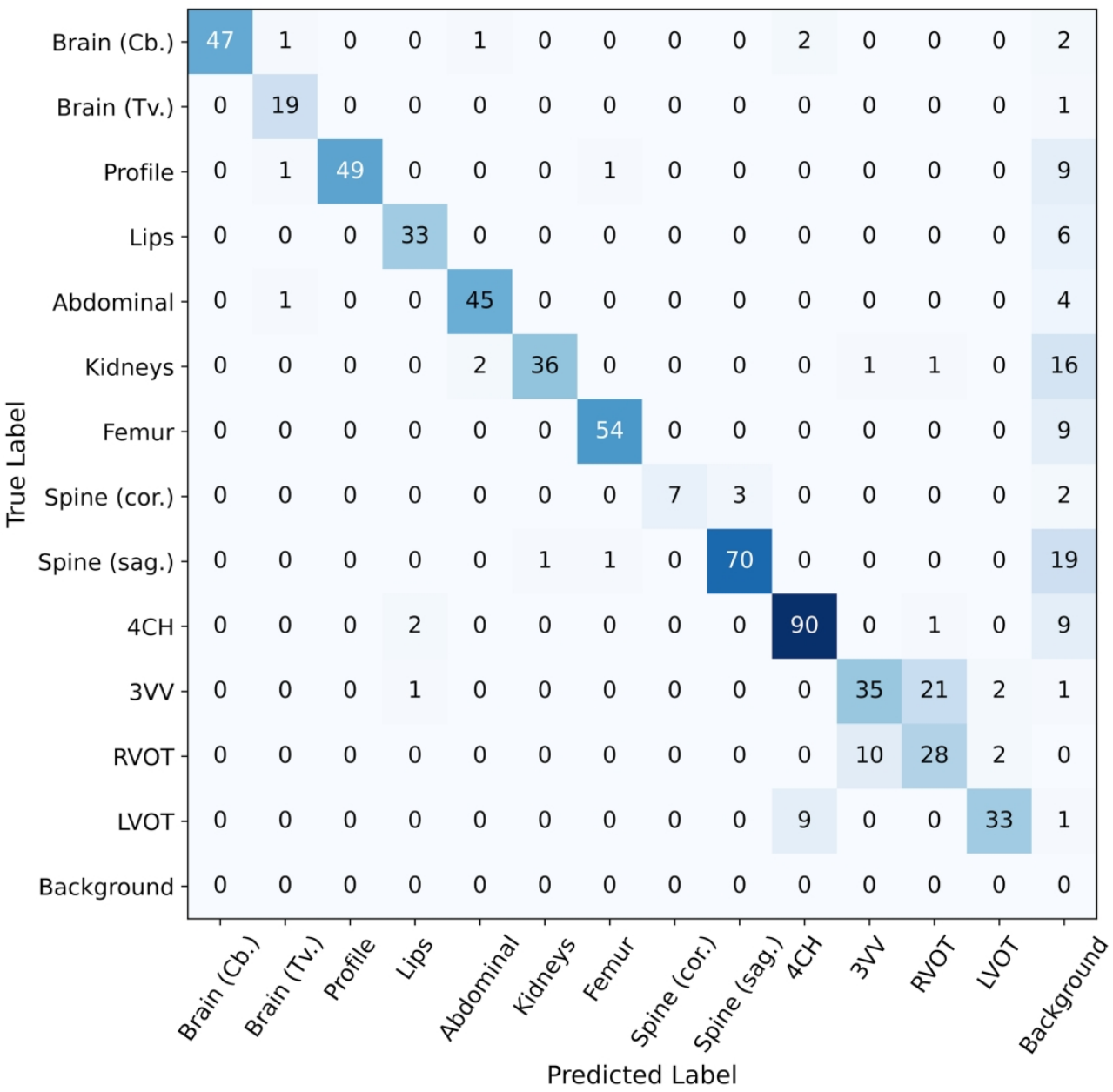

Figure 1. The confusion matrix demonstrates number of standard plane images classified using the neural net (SonoNet) versus manual annotation. The neural net failed at distinguishing reliably between some standard planes ( $3 \mathrm{VV}$ and RVOT), whereas other planes were classified with high accuracy (e.g. femur length or abdominal circumference).

$$
209 \times 204 \mathrm{~mm}(300 \times 300 \text { DPI })
$$




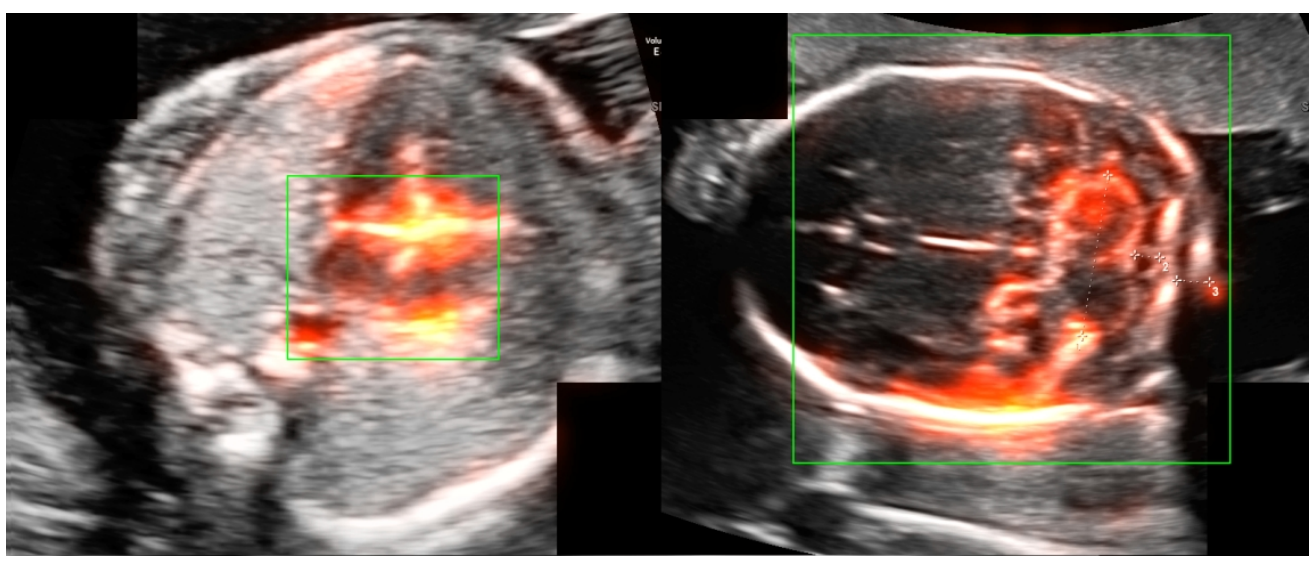

Figure 2. An example of visualizations using 'heat maps'. To the left: Correctly classified four chamber view. To the right: Correctly classified transcerebellar plane. In both images, the neural network only used part of the images for classification (only crux cordis and not the apex; only the cerebellum but not the anterior complex), in contrast to the criteria used by human experts.

$33 \times 13 \mathrm{~mm}(1200 \times 1200$ DPI $)$

This article is protected by copyright. All rights reserved. 